\title{
Nun auch noch Data Governance!
}

\section{Liebe Leserinnen und Leser,}

in unserer Ausgabe 7/2019 haben wir uns intensiv mit neuen Aufgaben beschäftigt, die im Zuge der Digitalisierung auf die Leiter der Finanzfunktion und die Controller zukommen. Einige davon betreffen den Umgang mit Daten und sprechen dabei zwei ganz unterschiedliche Themenbereiche an. Auf der einen Seite geht es um die Sicherstellung der Qualität der Daten. Dies betrifft sowohl die Qualität einzelner Datenquellen als auch die Konsistenz von Daten, die aus unterschiedlichen Quellen stammen. Auf der anderen Seite geht es um die Frage, wer auf die Daten zugreifen kann und darf und wie vermieden werden kann, dass die Daten in die falschen Hände geraten. Hier stehen Richtlinien und Standards im Fokus.

Themen dieser Art stoßen bei Controllern nicht immer auf Begeisterung. Sie sind eher „erbsig“, häufig IT-technisch anspruchsvoll und verlangen eine gewisse Begeisterung für die Präzision komplexer Regelwerke. Kurz: Sie sind auf den ersten Blick meilenweit vom geliebten Leitbild des Business Partners entfernt.

Warum treten diese - nicht neuen - Aufgaben aktuell so stark in den Fokus? Hierfür lassen sich zwei Schlagworte heranziehen, die jeder kennt: Big Data und Demokratisierung der Daten. Big Data adressiert den Punkt, dass heute die Landschaft verfügbarer Daten sehr heterogen geworden ist. Sie geht deutlich über die angestammten (wenigen) Datentöpfe hinaus, die zumeist aufwendig qualitätsgesichert waren und es auch weiterhin sind, wie etwa die der Finanzbuchhaltung. Entsprechende Anstrengungen fehlen für die neuen Datenquellen bisher weitgehend oder sind noch deutlich zu verstärken. Dies bedeutet Kärrnerarbeit. Nur so kann aber ein „Garbage in Garbage out“ vermieden werden. Für die Controller sind die neuen Datenquellen - wie etwa Prozessdaten - vielfach noch sehr fremd; sie haben keine Erfahrung mit ihrer Qualität und den Faktoren, die sie beeinflussen. Sie sind hier auf die $\mathrm{Zu}-$ sammenarbeit mit anderen Akteuren angewiesen, die aber auch erst noch gefunden und gebunden werden müssen.

Die Demokratisierung der Daten speist sich aus der Möglichkeit, dass durch die neuen IT-technischen Lösungen im-

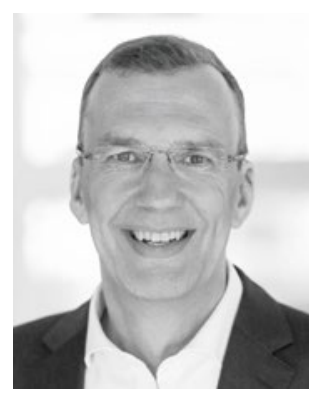

Utz Schäffer

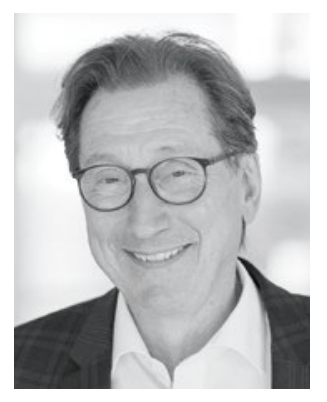

Jürgen Weber mer mehr Nutzer auf immer mehr Daten zugreifen können. „Self-Service-BI“ steht dabei als Beispiel dafür, dass eine solche Entwicklung bewusst angestrebt wird. Allerdings geht es hier nicht unbedingt um eine Maximierung der individuellen Transparenz. Nicht jeder sollte alles wissen können. Er wäre damit schnell überfordert. Außerdem sollte nicht jeder alles wissen dürfen. Viele Daten sind aus den unterschiedlichsten Gründen heraus schutzbedürftig. Mögliche neue Erkenntnis aus hoher Transparenz versus Datenschutz: Controlling und die IT müssen hier immer wieder gemeinsam nach einer tragfähigen Lösung suchen, die beide Aspekte miteinander verbindet. Spätestens an dieser Stelle wird deutlich, dass Data Governance weit über Technik hinausgeht und ein spannendes Management-Feld bedeutet. Dieses müsste auch für die Controller attraktiv sein, die eher Business Partner sein wollen!

Viel Spaß bei der Lektüre wünschen Ihnen
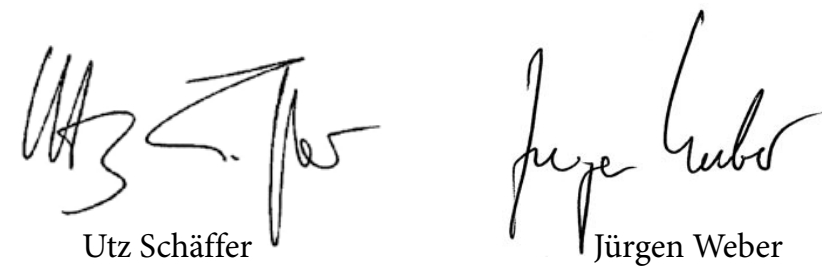